\title{
Impact of TV Commercials on Persuasive Speech: A Critical Review
}

\author{
Minowara Begum
}

\begin{abstract}
With the growth of global economy, TV commercials not only have added a new dimension to the communication process throughout the world, but also have been widely recognized as authentic materials that can be beneficial to the need-based learners. This paper attempts to analyze the performance of two groups of students' persuasive speech presentations, one in the traditional mode and the other was with TV commercials to examine the impact of using TV commercials in the language classroom. This paper includes the result of a survey conducted on the students of Stamford University Bangladesh. It also discusses the limitations of using TV commercials in the context of learning EFL (English as Foreign Language)/ESL (English as Second Language), particularly in Bangladesh.
\end{abstract}

Key words: TV commercials, Authentic materials, Persuasive speech, Impact

\section{Introduction}

The persuading nature and worldwide accessibility of TV commercials have made them an invaluable source of authentic materials to be used in classrooms in the context of EFL (English as Foreign Language) and ESL (English as Second Language). In a very short span of time, the premeditated attempts of commercials leave an undeniable impression on our minds, arises certain kind of emotion that also lure us to consume the advertised products. Therefore, the appealing nature of commercials affirms its effective applicability for teaching materials in language classroom especially in case of teaching "Persuasive Speech". Again, if the students can find out the manuals that advertisers use to increase the irresistible power to make a quick persuasion in commercials, it will surely accelerate learners' understanding of various aspects of persuasion.

Similarly, the use of commercials in the speech classroom can be a rewarding experience for the language teachers. Facilitators can easily utilize advertisements as teaching resources that are beneficial for students in creating an interest in learning. A compelling TV commercial as a dominant device can create a greater impact on the audience's psychology. Smith and Rowley (1997) illustrate the following:

A second benefit of the commercial is that it is designed to have an impact. Viewers remember what they hear, sometimes even when they do not understand the message, because the visual and musical reinforcement is strong and lasting. We often hear a 
slogan or a tune rolling around in our heads hours after we have turned off the TV. (Designed for an Impact, para. 1)

\section{Study purpose}

The purpose of this study is to measure the effectiveness of using TV commercials in Public Speaking Course particularly in teaching persuasive speech. It also intended to evaluate the impact of TVcommercials on the learners and their learning processes.

\section{Literature review}

\section{Reasons of using TV commercials in ESL/EFL classes}

The use of TV commercials in language classrooms is beneficial for language learners for certain reasons. First, though learners need to know the function of language for communication, most often English is taught separately from the context where it is used in society. To make the language learning interesting, and to ensure students' active participation, teachers need to enliven their classes with authentic materials. Jordan (1997) refers to, 'authentic texts as texts that are not written for language teaching purposes'. (p.113). It also goes with the idea of Nunan (1999) that authentic materials help bring the contact to life, and ultimately make learning and using language more meaningful, and ultimately easy for students (p. 212).

Davis (1997) explicates that commercials have not been fabricated, arranged, or simplified for the consumption of the language learner.(Rationale Behind Using TV Commercials Messages: Commercials are authentic, para.1). In fact, the languageteaching profession has long had advocated of the classroom use of advertising as authentic material (e.g. Davis, 1997; Doering, 1993). Commercials provide an opportunity to learn about the use of language and also the authentic social context where it is used. Nunan (1989) identifies authentic material as any material which has not been specifically produced for the purposes of language teaching (p. 54).

Advertisements are a great source for the reflection of the society. Winnail has argued that textbooks are restricted as most language textbooks, which are used in classrooms, are written for non-native learners and they are not authentic enough for practical usage (as cited in Williams \& Rates, 2006, p.4). According to Tuzi, Mori and Young (2008), 'Television commercials can provide a treasure trove of language learning opportunities' (Conclusion section, para.1). Watching commercials exposes learners to true-life language, demonstrating them the extent to which they can handle real-world inputs successfully. Moreover, seeing the language used in real life contexts in advertisements also helps the students to become autonomous learners. Exposure to commercials in the classroom engenders in students a stronger sense of language autonomy-the feeling that they can actually function linguistically beyond its walls (Davis, 1997).

Second, the use of authentic materials in language classroom also enhances the scope of doing authentic assessment which allows students to apply their acquired knowledge and construct meaningful responses. Callison (1998) defines authentic assessment as an evaluation process that involves multiple forms of performance measurement reflecting the student's learning, achievement, motivation, and attitudes on instructionally-relevant activities (p.1). As TV commercial is one of the most available authentic materials, teachers can design more engaging tasks by using it such as oral presentations, 
individual projects, demonstrations, performances and assignments, etc.

Third, the brevity of TV commercials also enhances its suitability in language classrooms. It is not a difficult task for language teachers to select, manipulate and prepare a TV commercial for applying into their classrooms. TV commercials are short, on average lasting 30 to 50 seconds. Their lengths are ideal for new language learners (Davis, 1997; Erkaya, 2005).

Moreover, the most striking feature of an advertisement is its distinctive linguistic features that can convince the audience. It is different from the common language as it follows a style of immediate impact and quick persuasion (Pop \& Sim, 2010). In addition to that, the language of commercials is simple, purposeful, rich, striking and engaging. It can attract its audience instantaneously through its persuasive slogans, catchy songs, and striking visual images which are both visually and linguistically memorable (Smith \& Rawley, 1997).

In addition to that, advertisements contain audio-visual aids which create an intrinsic motivation for students as they contain innovative devices. Martin (2012) states, 'Advertising messages trigger emotions, grabbing and holding the attention of an audience, and therefore stimulate students' interest and motivation' (p.162).

Davis (1997) also expresses the following:

CMs are designed to capture the attention of the viewer. Commercials present their messages in words and pictures, which complement and support each other. Furthermore, advertisers purposely bombard listeners with key words and slogans to the beat of some catchy tune that stays imprinted in students' minds for days. (Commercials contain visual, verbal, and written images section, para 1)

Finally, as the world's lingua franca, English is preeminent among the languages used in advertisements. So, every day students receive a certain amount of exposure to English language through advertisements that enrich their knowledge in English language. As Piller (2003) points out, 'English is the most frequently used language in advertising messages in nonEnglish speaking countries (besides the local language, of course)' (p.175).

\section{Definition of persuasive speech}

According to Lucas (2001), the persuasive speech is:

A speech designed to change or reinforce the audience's beliefs or actions. Most of us do a certain amount of persuading every day, although we may not realize it or call it so. Public speaking to persuade is essentially an extension of this. It is an attempt to convert a whole group, not just an individual, to your point of view on a particular subject (p. 368).

Persuasive speech invites the audience to adopt a particular view and take action accordingly, and the persuasive speaker attempts to achieve this purpose through appealing to the emotion, values and beliefs of the audience.

\section{Definition of TV commercial}

In simple words, a commercial advertisement on television (generally abbreviated to TV commercial) can be defined as a television programming which is produced and paid for by an organization and used as a medium 
for informing people of something by drawing attention to it.

Moreover, an advertisement may be defined as a public notice. Harris and Heldon (1962) define advertisement as a medium 'designed to spread information with a view to promoting the sales of marketable goods and services' (p. 40), or defined as a vital marketing tool a well as a powerful communication force. Furthermore, Bovee (1992) defines advertising as the nonpersonal communication of information usually paid for and usually persuasive in nature about products, services or ideas by identified sponsors through the various media' (p.7).

\section{Rationale for choosing advertisements in persuasive speech class}

After completing Fundaments (ENGL 100) and English Composition (ENGL 101), students of Stamford University Bangladesh need to enroll for Public Speaking course. This course is designed to help students to improve their oral skills in order to make them better speakers. According to Lucas (2001), 'the ability to speak (and write) persuasively will benefit an individual in every part of their life from personal relations to career aspirations' ( $p$. 368).

Like self-introductory and informative speech, it is compulsory for students to give a presentation on persuasive speech. Even though persuasive speech is supposed to be delivered extemporaneously, it has been observed that most of the students do well in other speeches.In case of persuasive speech presentations, their performance is not up to the standard. Most students miss the essence of persuasion in their speeches. Even after explaining the relevant theoretical concepts of persuasive speech, in time of their delivery, most often, they fail to determine and apply the elements required to grab the attention of the target audience. Considering them, to help students, I decided to use advertisements in my class as those are created to persuade people and always designed to address a specific audience. For this purpose, I have selected Proactiv Solution as it is rated as one of the most persuasive TV advertisements (http:/ / www.toptenz.net/top-10-persuasive-tvads.php). It first appeared on MTV, MTV2, E!, Style in July, 2006 with celebrity endorsement from Lindsay Lohan.

\section{Reasons for selecting Proactiv commercial}

Title of Commercial:Proactiv solution

Duration: 2 minutes and 3 seconds

Celebrity Endorsement: Lindsay Lohan

The process of selecting the advertisement is an important aspect of the whole approach as its effectiveness depends on choosing the right one. Apart from having the rating, I have selected Proactiv commercial to use it in my classroom also for the following reasons:

It is short, lasting not more than 3 minutes, so the students do not lose their interest and concentration.

The advertisement covers various persuasive techniques and follows a specific organization style.

- Emphasis is given on the exposure of language in the advertisement, and no jingle has been included.

\section{Aspects of TV commercial that were shown to the students}

Being an instructor of Public Speaking course for several trimesters, I have noticed that in 
time of preparing and presenting persuasive speech, most students face problems because they lack knowledge of incorporating different techniques to make their speech more convincing. In addition to that, most often they struggle with structuring their speech. Therefore, I decided to use Proactiv commercial in my class as it covers various persuasive techniques and follows a specific organization style.

\section{How the commercial was used in persuasive speech classroom}

Before showing the advertisement in the classroom, students were made familiar with different persuasive techniques and useful organizational method. So, when those techniques and organizational patterns were explained to students with the help of the commercial, it became easier for students to identify and internalize the usage of those techniques and organization method.

To make the learning effective, some steps were followed while introducing the commercial. The commercials were shown twice to students. At first, an onscreen commercial was shown without giving any pause, so that the students can have an overall impression of the advertisement. Then, when it was played for the second time, students' attention was drawn to certain techniques and organization methods by giving pause several times to highlight some aspects.

\section{Introducing techniques of persuasion through the selected commercial}

The most common techniques that are found in most advertisements are discussed below one after another along with their application in the selected commercial.
I) Persuasive language in advertisements:

First of all, the most noticeable feature of an advertisement is its language. Generally, all advertisements frequently use verbs, phrasal verbs and adjectives, rhetorical questions, advertising slogans with a purpose to lure the audience.

In Proactiv commercial we also find some commonly used verbs and adjectives. They are as follows:

Use of verbs in the 'Proactiv' commercial - help, get, like, try, find, prevent, heal, work, use, clear, want, choose, keep, put.

- Use of Adjectives in the 'Proactiv' commercial - happy, best, standard, easy, good, free, special, great, healthy, proud.

Rhetorical Questions - A question to which no answer is expected, often used for rhetorical effects.

- Used rhetorical questions in the Proactiv commercial:

I) Lindsay asks, “Wouldn't you like to be clear too?"

II) When Lindsay asks, "Why not try it, what have you got to lose?" She pressures the audience into wanting to buy the product.

Advertising slogans - Advertising slogans are cleverly worded and manipulated for the masses. For example:

Slogan used in the Proactiv commercial - I'm proud to be a 'Proactiv'. 
II) Persuasive Tone: In a commercial, the tone and attitude is designed to convince the consumer to agree with the producer.

Used tone of the Proactiv commercial: Friendly, casual, enthusiastic, easygoing, convincing, funny.

III) Bandwagon - Bandwagon uses the argument that a person should believe or do something because "everybody else" does, otherwise he or she will be left out.

Application of this technique in the Proactiv commercial: "Now it's your chance to join Lindsay and millions more, who clear their skin with 'Proactiv Solution'?"

IV) Bribery - If the consumer buys the product, they will get something free or with a discount.

"Try Proactiv now and get a special free gift by receiving a "free" refining mask with your order. Thus, the audience is more tempted to purchase Proactiv.

V) Experts - Someone with authority tells the audience to buy it. Scientists and experts tell how important something is.

- The commercial claims that two trained dermatologists from Stanford developed proactiv.

VI) Explicit Claims - Direct and clear claim

- Proactiv guarantees your face will be clean, healthy and blame free, or your money back.

Proactiv heals acne, it works like skin care.
VII) Emotional Appeals - Make viewers feel for certain emotions, such as excitement, sadness, or fear. Audience transfers that feeling to the product.

- Used technique in the Commercial Fear of breakouts has been created. A fearful and threatening environment has been created through this commercial.

VIII) Intensity - Hyping up the product: "Greatest, best, lowest, better, improved, amazing, incredible."

- Named best acne treatment by Allure magazine.

IX) Repetition - Repeating the message or words within the commercial.

- The words Proactiv, acne, breakouts, clear etc. are repeated several times throughout the commercial.

\section{X) Scientific Evidence and Technical Facts}

- Information that provides detailed, impressive-sounding scientific or technical information.

- The commercial states that with Proactivs' proven three steps systems (Step 1 - Cleanse, Step 2 - Tone, Step 3 Repair are shown on the screen), the audience will be able to heal acne.

XI) Warm \& Fuzzy - Sentimental and emotional ideas or images.

- Lindsay Lohan expresses that she feels proud to be a Proactiv.

\section{Introducing the organization method through the selected commercial}

Students are usually instructed to follow Monroe's Motivated Sequence as it is easy 
to follow and extensively used in most of the commercials. Proactiv follows this method of organization, and for that reason, I have selected this commercial to help my students organize and structure their speech better. In my class, after giving a short description of Monroe's Motivated Sequence, I analyzed how this has been followed in the Proactiv commercial.

Monroe's Motivated Sequence is a technique for organizing persuasive speeches that spurs people to action which is developed by Alan Monroe, a professor of speech at Purdue University in the 1930s. According to Lucas (2001) “Monroe's Motivated Sequence follows the process of human thinking and leads the listeners step by step to the desired action. One indication of its effectiveness is that it is widely used by advertisers" (p. 386).

The most widely used organization pattern that is found in most TV Commercials are discussed below along with its application in Proactiv commercial.

\section{Monroe's motivated sequence-the five steps}

I) Attention: The commercial grabs the attention of the audience when Lindsay Lohan, a beautiful person and a celebrity, appears on the screen and introduces herself with the statement "Hi, I'm Lindsay Lohan" at the very beginning of it.

II) Need: Lindsay Lohan then shows the audience that there is a problem with the existing situation by asking the questions: "Do you stress out about your skin?", "Do you freak out when you break out over night?". She creates an urge within the audience's mind with this rhetorical question: "Wouldn't you like to be clean too?" As this problem is a common one, by asking this rhetorical question she is able to engage the audience directly with the subject.

III) Satisfaction: Lindsay Lohan provides a solution to the problem by stating "Well, help is on the way. It's called Proactiv solution."

- "Proactiv heals acne, the best things it's super gentle. So it works everyday like skin care."

IV) Visualization: With Proactiv's proven three step systems, you can heal acne today and prevent future breakouts tomorrow.

(There is an animated representation onscreen of healing acne).

It's standard. It has three steps. In addition, it is easy to take with you. It is also easy to travel with which I find really good. Actually, I think I will keep some in the car too.

(Lindsay displaying impressing expressions)

Proactiv guarantees that your face will be clean, healthy and blame free, or your money back. So with a sixty-day guarantee, why not try it? What have you got to lose?

The effectiveness of the product is depicted from the use of Proactiv, portraying contrasting pictures of Lindsay's face with acne before using Proactiv and later on her acne free and radiant skin after using Proactiv.

V) Action: It convinces the audience that the ad informs them of the address, contact number, email address etc. are required to buy the product. 
Act quickly and receive free upgradepriority mail shipping. Call one eight hundred, five three seven, ninety nine hundred.

\section{Research methodology}

\section{The participants}

All the participants in this study were undergraduate students from a private university, namely Stamford University of Bangladesh. The participants were the students of two sections (batch 49) from the department of Computer Science and Engineering (CSE). The students were particularly chosen for the study because they were doing a public speaking course in which they had to give persuasive speech presentations.

\section{Methodology}

In persuasive speech presentations, the performance of the students was evaluated based on five criteria: language skills, speaking style/delivery, use of reasoning and evidence, effective use of visual aids and overall organization (see the rubric in the appendix section for the grading criteria). In this study, to evaluate the impact of TV commercials on the learners and their learning processes,performance assessment, a type of authentic assessment was administered. Stiggins (1987) states that performance assessments call upon the examinee to demonstrate specific skills and competencies, that is, to apply the skills and knowledge they have mastered (p. 34). For this purpose, in total the presentation performance of 60 students was assessed. The participants were divided into two groups, each group with 30 students. To see the effectiveness of using commercials in persuasive speech class, a commercial was used deliberately with one group (Group A) and using it with the other group (Group B) was avoided. Both groups of students were selected as they were from the same department and from their earlier performances in the class; it was observed that they shared almost the same extent of intellect and comprehensive ability. To get the authentic results, with both groups the same text The Art of Public Speaking ( $7^{\text {th }}$ edition) written by Stephen E. Lucas was used; all other classroom materials were kept identical and they received the same lectures. Finally, they were asked to give presentations on the same topic for performance assessment. Throughout the procedure, only one exception was made; Group A was exposed to a TV commercial and Group B was not.

After the presentation, a survey was conducted on 30 students who were shown commercial (Group A) in the classroom. In addition to that, a questionnaire consisting of seven close-ended questions was circulated among the students of the same group. Therefore, it can be seen that in this study data was collected by assessing students' performances and by carrying out a survey. Furthermore, in this paper, the author has also shared some of her opinions based on her experiences. Therefore, the nature of the study is - mixed method - as it has both qualitative and quantitative components.

\section{Data analysis procedure}

Independent sample t-test was used to find out the significant mean difference between performances of the two groups. The result of the survey conducted among the participants was counted into percentage.

\section{Findings and discussions}

For performance assessment, in their persuasive speech presentation, all students (Group A and Group B) were told to promote a product or service that interests them. They were free to use any creative 
techniques to reach their goal of promoting any product or service and had to show how the product or service was excellent and changes the attitudes and behavior of the audience toward it by being persuasive. The students were 19-22 years old, and they were full of enthusiasm. The analysis of their presentation is as follows:

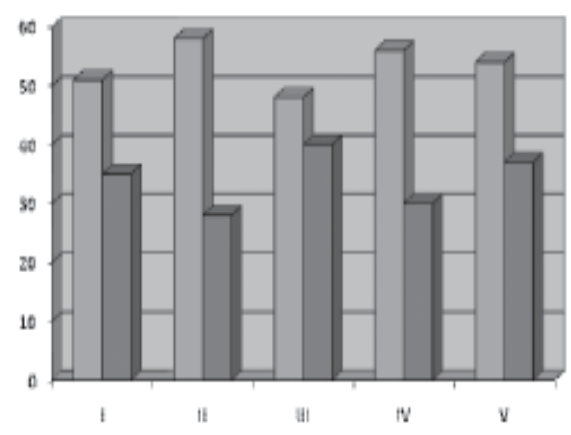

\section{Observed Categories}

Figure 1: Marks obtained in each category by Group A and Group B

Different Categories:

Category I= Language Skills

Category II = Speaking Style/Delivery

Category III = Use of Reasoning and Evidence

Category IV = Effective Use of Visual Aids

Category $\mathrm{V}=$ Overall Organization

Marks allocated for each category $=2$

Total presentation marks $=2+2+2+2+2=10$

The bar graph gives a comparison between marks obtained in the above mentioned five categories by the students of Group A (who were shown the commercial) and Group B (to whom the commercial was not shown). It can be observed that Group A got more marks in each category than Group B.

Total presentation marks for each student was 10. Each category carried equal marks that is 2; each group had 30 students; therefore, by multiplying the marks and number of students, total marks in each category was 60 and total marks of 5 categories was 300 $(60 \times 5=300)$.

The effectiveness of using advertisements has been reflected in presentations of the students of group A. The highest score obtained by Group A was 58 in category (II), whereas, for Group B, the highest score was 40 in category (III). The marked difference between the groups took place in category (II), here. Group A got 58 and Group B got 28, and the difference in marks was 30. The least difference between the groups was in category (III), where Group A scored 48 and Group 2 scored 40, and the difference of marks was only 8 . The second highest difference occurred in category (IV), where Group A got 56 and Group B received 30 and the difference of marks was 26. In the remaining categories, Group A received 51 and 54 and Group B received 35 and 37 in category (I) and (V) respectively.

To ascertain whether there were any differences between the performances of the two groups of students in terms of efficacy of TV commercial, the total mean score difference and each categorical mean difference were calculated through an independent t-test sample. The result of an independent sample t-test is presented below: 
Table- 1: Result of Independent sample t-test used for performance assessment

\begin{tabular}{|l|l|l|l|l|l|l|}
\hline & Group & Mean & SD & MD & t-value & Sig. (P) \\
\hline \multirow{2}{*}{ Total } & Group A & 8.90 & 0.67 & \multirow{2}{*}{3.23} & 5.1 & \multirow{2}{*}{$000^{*}$} \\
\cline { 2 - 5 } & Group B & 6.67 & 0.96 & & & \\
\hline Category I & Group A & 1.70 & 0.29 & .53 & 7.44 & $.000^{*}$ \\
\cline { 2 - 5 } & Group B & 1017 & 0.27 & & & \\
\hline Category II & Group A & 1.93 & 0.11 & 1.0 & 21.55 & $.000^{*}$ \\
\cline { 2 - 5 } & Group B & 0.93 & 0.23 & & & \\
\hline Category III & Group A & 1.60 & 0.16 & 0.27 & 5.53 & $.000^{*}$ \\
\cline { 2 - 5 } & Group B & 1.33 & 0.21 & & & \\
\hline Category IV & Group A & 1.87 & 0.16 & 0.87 & 17.06 & $.000^{*}$ \\
\cline { 2 - 5 } & Group B & 1.00 & 0.23 & & & \\
\hline Category V & Group A & 1.80 & 0.21 & 0.59 & 10.05 & $.000^{*}$ \\
\cline { 2 - 4 } & Group B & 1.23 & 0.23 & & & \\
\hline
\end{tabular}

$\mathrm{SD}=$ Standard Deviation, $\mathrm{MD}=$ Mean Difference

*Significant at $\mathrm{P}<.01$

The total mean score was 8.9 ( \pm .67$)$ for Group A and $6.67( \pm .96)$ for Group B. The presentation scores of Group A and Group B were compared using an independent samples t-test. There was a significant difference between the scores of Group A and Group B as t value is 15.1 at $\mathrm{p}<.01$.

When considering different categories, it is found that all of the other categories are significantly varied across Group A and Group B at $\mathrm{P}<.01$. Therefore, the commercial had a significant impact on the students who received it as a part of their instruction in the persuasive speech class.

From the above mentioned findings of the performances of two groups of students, it can be observed that commercials had a positive influence on persuasive speech presentation. The highest difference between the two groups' performance occurred in category II - speaking style/ delivery. The reason can be that TV commercials always try to grab the attention of the audience by using persuasive words, phrases, slogans and rhetorical questions as their persuasive technique. The students, with whom the commercial was used, could easily identify this technique and was very conscious about incorporating some persuasive words, catchy slogans and rhetorical devices. On the other hand, the students with whom the commercial was not used though they had theoretical knowledge about this technique; however, most of them failed to utilize it in their performance as they did not see the practical application of the technique. The least difference between the two groups' performance occurred in category III - use of reasoning and evidence. The reason could be that both groups learned about argumentative paragraph as a part of their English composition course in their previous trimester. Since students need to use sound reasoning to support their arguments in argumentative paragraphs, they knew about this persuasive technique very well and both groups could use it effectively in their presentations. 
It was observed that students who were shown advertisement in classroom showed noticeable enthusiasm and confidence compared to students of the other group. Even all the reluctant and a bit shy students of Group A showed interest as they got something in front of them as a model. As a result, their positive responses and productions made the presentation day brighter. To know more about the influence of the TV commercial on their persuasive speech, a survey was conducted among the students of Group A; their responses to the close ended questions were as follows:

\section{Findings and discussion of students' responses}

In the first question, the participants were asked whether the TV commercial helped them to get better understanding of persuasive speech and it was found that all theparticipants (30) considered them to be helpful. It is clear from this survey that the students had received some useful ideas from the commercial that helped them to learn better about persuasive speech.

\begin{tabular}{|c|c|c|c|}
\hline Questions Topic & $\begin{array}{c}\text { Answer } \\
\text { Type }\end{array}$ & $\begin{array}{c}\text { Number of } \\
\text { students }\end{array}$ & $\begin{array}{c}\text { Percentage } \\
(\%)\end{array}$ \\
\hline \multirow{2}{*}{$\begin{array}{l}\text { 1. Does this commercial help you to } \\
\text { understand persuasive speech } \\
\text { better? }\end{array}$} & Yes & 30 & 100 \\
\hline & No & 0 & 0 \\
\hline \multirow{2}{*}{$\begin{array}{l}\text { 2. Do you find the persuasive words } \\
\text { in the commercial worthy of using } \\
\text { in your persuasive speech? }\end{array}$} & Yes & 27 & 90 \\
\hline & No & 3 & 10 \\
\hline \multirow{2}{*}{$\begin{array}{l}\text { 3. Do you think the persuasive tone } \\
\text { of the commercial can be } \\
\text { incorporated into your persuasive } \\
\text { speech? }\end{array}$} & Yes & 24 & 80 \\
\hline & No & 6 & 20 \\
\hline \multirow{2}{*}{$\begin{array}{l}\text { 4. Do you get any idea from the } \\
\text { commercial of making your speech } \\
\text { more creative? }\end{array}$} & Yes & 21 & 70 \\
\hline & No & 9 & 30 \\
\hline \multirow{2}{*}{$\begin{array}{l}\text { 5. Do you find the gesture, posture } \\
\text { and facial expressions of the } \\
\text { commercial useful for your } \\
\text { persuasive speech? }\end{array}$} & Yes & 24 & 80 \\
\hline & No & 6 & 20 \\
\hline \multirow{2}{*}{$\begin{array}{l}\text { 6. Does this commercial help you } \\
\text { to determine and apply the } \\
\text { elements required to draw the } \\
\text { attention of a particular } \\
\text { audience? }\end{array}$} & Yes & 27 & 90 \\
\hline & No & 3 & 10 \\
\hline \multirow{2}{*}{$\begin{array}{l}\text { 7. Do you find learning persuasive } \\
\text { speech through using TV } \\
\text { commercial motivating and fun? }\end{array}$} & Yes & 30 & 100 \\
\hline & No & 0 & 0 \\
\hline
\end{tabular}


In the second question, they were asked whether they found the persuasive words used in the commercial to be worthy of using in their persuasive speech. $90 \%$ of the participants agreed that they were. It is revealed that the language used in the advertisement was perceived to be suitable for usage in their own speeches by the students.

In the third question, the participants were asked if they think the persuasive tone of the commercial could be incorporated or used into their persuasive speeches. In response, $90 \%$ of them stated that it could be done. Persuasive tone is one of the most important features of persuasive speech, and from this survey, it can be understood that the use of it in advertisements is prominent among the components of persuasion. Incorporating persuasive tone in persuasive speech is comparatively easy, as it does not require emphasis on grammatical accuracy or a wide range of vocabulary. Rather, it is oriented to the skill of communication.

Then, the participants were asked whether they got any idea from the commercial of making their speeches more creative. 70\% of the students responded that they did get such ideas from the advertisement. Advertisements use innovative devices for grabbing the attention of the audience, some of which can be very helpful for using in persuasive speeches and making them effective, if the situation where they are being used is appropriate for such an action.

Next, the students were asked if they found the gesture, posture and facial expressions used in the commercial to be useful for their persuasive speeches. $80 \%$ of them answered that they found these features to be useful. Advertisements often show beautiful people or present celebrity endorsers to convince their audience to buy the products. The gesture, posture, facial expressions, etc. of these people are usually aesthetically pleasing and quite attractive to the audience, and can be effective for persuasion purposes.

Afterwards, the students were asked whether the commercial helps them to determine and apply the elements required to draw the attention of a particular audience, $90 \%$ of the students agreed that it does. Presentation techniques vary in advertisements according to the age, tastes, and interests, social and cultural values etc. As a result, students can learn that to persuade different audience, they need to use different persuasive elements.

Lastly, all of the participant students agreed that learning persuasive speech through using advertisements is motivating and fun. Besides attempting to convince the audience to buy products, advertisements serve entertainment purpose as well, which can encourage people; especially the students as they are young and enthusiastic.

\section{Limitations of the study}

As the research was conducted on a small scale where sixty students took part in the investigation process, we cannot generalize that the concept that TV commercials can be used as an effective classroom material to enhance students' persuasive speech skill. Another limitation was that only one commercial was used for the study. It would be more effective and efficient if more commercials were used and shown to more students; the result might have been a little bit different.

\section{Recommendations}

Other forms of advertising such as print advertising (newspaper, brochures, magazines, flyers), broadcasting advertising (radio, internet, mobile), outdoor advertising (bill boards, kiosks, trade shows, events), direct mail (catalogues, flyers, letters, postcards), street advertising, games (mobile and 
computers), etc. can be used to make the class more stimulating.

- Teachers can tell students to create visuals, e.g., posters, flyers, collages to persuade a designated audience to take action on a particular issue or topic.

There is a claim that advertising debases English as sometimes deviant words are used in advertisements so the students should be made aware of this by the instructor.

- When using commercials in the classroom, it is critical to select commercials that are within the range of students' linguistic abilities and it should be ensured that the attires, photographs and other illustrations, words or linguistic and other expressions are culturally acceptable, audio materials are not too difficult to use or comprehend etc. Otherwise the required impact will not be attained.

\section{Conclusion}

It can be observed from the findings that TV commercials can contribute significantly to persuasive speech learning process and their effectiveness in language classroom has been revealed in this study as reflected in better performances of the students who were shown the commercial. As TV commercials shape our perception of reality, it opens a new door in students' faculty that enables them to appreciate and analyze critically the commercials they watch every day and grow up as a good persuasive speaker. They can discover elements of persuasion in advertisements by themselves and use those elements in their real life in every occasion when they need to persuade or convince someone. Thus, in the second language learning classroom, both in EFL and ESL environments, teachers can make a big difference in the persuasive speech class through the use of TV commercials.

\section{About the author}

Minowara Begum is a Lecturer in the Department of English at Stamford University Bangladesh.She completed B.A. (Hons) and M.A. in Applied Linguistics and English Language Teaching (ELT) from the University of Dhaka. Her areas of interest include English language Teaching (ELT), Technology and ELT, Discourse Analysis and Material Development.

\section{References}

Bovee, C.L. \& Arens, W.F. (1992). Contemporary advertising, Boston: Richard D. Irwin.

Callison, D. (1998) .Authentic Assessment, School Library Media Activities Monthly14(5), 1-4.Retrieved on $9^{\text {th }}$ Nov. 2014 from http://www.ala.org/aasl/ sites / ala.org.aasl/files/content/ aaslpubsandjournals/slr/edchoice/ SLMQ_AuthenticAssessment_InfoPower.pdf

Davis, R. (1997). TV commercial messages: An untapped video resource for teaching content-based classes. The Language Teacher, 21(3), 13-15. Retrieved on $15^{\text {th }}$ Jan. 2014 from:http://www.jaltpublications.org/tlt/files/97/mar/ davis.html

Doering, E.J. (1993). Gaining competence in communication and culture through French advertisements. French Review, $66,(3), 420-432$. Retrieved on $28^{\text {th }}$ Jan. 2014 from: http://www.jstor.org/ d i s c o v e r / $10.2307 /$ 397435? uid $=3737584 \&$ uid $=2129 \&$ uid $=2$ \&uid $=70 \&$ uid $=4 \&$ sid $=21104242332733$

Erkaya, O.R. (2005). TV commercials as authentic tools to teach communication, 
culture and critical thinking. MexTESOL Journal. 29(1), 1-18. Retrieved on $2^{\text {nd }} F e b$. 2014 from: http:/ / files.eric.ed.gov / fulltext/ED494938.pdf

Jordan, R. R (1997). English for academic purposes: A guide and resource for teachers. Cambridge: Cambridge University Press.

Lucas, S. (2001). The art of public speaking. University of Wisconsin-Madison: McGraw-Hill Higher Education.

Martin, E. (2012). Using advertising to explore French language and culture in the classroom. Global Business Languages, 17(13), 161-170. Retrieved on $10^{\text {th }}$ Feb. 2014 from: http:/ / docs.lib.purdue.edu/ c gi / viewcontent.cgi? article $=1230 \&$ context $=$ gbl

Nunan, D. (1999). Second language teaching $\mathcal{E}$ learning. Boston: Heinle \& Heinle Publishers.

Nunan, D. (1989). Designing tasks for the communicative classroom. Cambridge: Cambridge University Press.

Piller, I. (2003). Advertising as a site of Language contact. Annual Review of Applied Linguistics, 23,170-183. Retrieved on 15 ${ }^{\text {th }}$ March 2014 from: http://languageonthemove.com/ $\mathrm{d}$ o w n l o a d s / P D F / piller_2003_advertising \% 201g\%20contact.pdf

Pop, M.A. \& Sim, A.M. (2010). The stylistics of advertising [Abstract]. Annals of the Oradea University, Fascicle of Management and Technological Engineering, IX (XIX), 183-188.Retrieved on 17 ${ }^{\text {th }}$ March 2014 from: http:/ / wenku.baidu.com/view / 1642fdcdda38376baf1fae26.html

Smith, A. \& Rawley, L.A. (1997). Using TV commercials to teach listening and critical thinking. The Journal of the Imagination in Language Learning and
Teaching, IV. Retrieved on $20^{\text {th }}$ March 2014 from: http:/ / www.njcu.edu/cill/ vol4/smith-rawley.html

Shepard,L.(1989). Why we need better assessments. Education Leadership,46,17.Retrieved on $10^{\text {th }}$ Nov. 2014 from http://www.ascd.org/ASCD/pdf/ j o u r n a l s / e d -1 e a d / el_198904_shepard.pdf

Stiggins, R. J. (1987). The design and development of performance assessments. Educational Measurement: Issues and Practice, 6, 33-42. Retrieved on $10^{\text {th }}$ Nov. 2014 from: http:/ / ncme.org/ linkservid/3E3AC538-1320-5CAE6E780DD57D5D8EE2/showMeta/0/

Tuzi, F., Mori, K. \& Young, A. (2008). Using TV commercials in ESL/EFL classes. The Internet TESL Journal, XIV (5). Retrieved on $18^{\text {th }}$ Jan. 2014 from: http:/ /iteslj.org/ Techniques/Tuzi-TVCommercials.html

Williams, R.T., \& Rates, P. (2006). Socially based learning: Using advertisement in the ESL classroom. Research Bulletin of Takamatsu University $y, 46,1-10$. Retrieved on $18^{\text {th }}$ Jan. 2014 from:http:/ /www.takamatsu-u.ac.jp/library/ 06_gakunaisyupan/kiyo/no46/ 46_001-010_williams.pdf 


\section{Appendix 1}

Scoring Rubric for Persuasive Speech Presentation

Presentation Title:

Name:

Group:

\begin{tabular}{|c|c|c|c|}
\hline Category & Scoring Criteria & $\begin{array}{l}\text { Total } \\
\text { Points }\end{array}$ & Score \\
\hline $\begin{array}{l}\text { 1. Language } \\
\text { skills }\end{array}$ & $\begin{array}{l}\text { - Correct and appropriate usage of } \\
\text { persuasive words/ phrases/ slogans/ } \\
\text { rhetorical questions }\end{array}$ & 2 & \\
\hline $\begin{array}{l}\text { 2. Speaking } \\
\text { style / } \\
\text { delivery }\end{array}$ & $\begin{array}{l}\text { - Speaker uses a clear, audible voice and } \\
\text { maintained persuasive tone through most of } \\
\text { the presentation } \\
\text { - comprehensible (rhythm, intonation, accent) } \\
\text { - Saintains eye contact with audience } \\
\text { - Speaker uses appropriate body language }\end{array}$ & 2 & \\
\hline $\begin{array}{l}\text { 3. Use of } \\
\text { reasoning } \\
\text { and } \\
\text { evidence }\end{array}$ & $\begin{array}{l}\text { - Presenter has solid and convincing } \\
\text { arguments } \\
\text { - Addresses particular audience at an } \\
\text { appropriate level } \\
\text { - Presents valid evidence to support speaker's } \\
\text { - arguments } \\
\text { - Less errors in reasoning }\end{array}$ & 2 & \\
\hline $\begin{array}{l}\text { 4. Effective } \\
\text { use of } \\
\text { visual aids }\end{array}$ & $\begin{array}{ll}\text { - } & \text { Audio/Visual components support the main } \\
& \text { points of the presentation. } \\
\text { - Visual aids are well arranged and do not } \\
\text { have distracting elements } \\
\text { - Graphs/figures are intelligible }\end{array}$ & 2 & \\
\hline $\begin{array}{l}\text { 5. Overall } \\
\text { organization }\end{array}$ & $\begin{array}{ll} & \text { Specific objectives } \\
\text { - } & \text { Logical structure (concrete topic sentence in } \\
\text { introductory part, well-developed body } \\
\text { and conclusion) }\end{array}$ & 2 & \\
\hline Score & Total Points & 10 & \\
\hline
\end{tabular}

\section{Appendix 2}

\section{Survey Questionnaire}

This questionnaire is designed to conduct a research on "Impact of TV Commercials on Persuasive Speech: A Critical Review"

The major objective of this research is to investigate the impact TV commercialson persuasive speech class.

Please complete the following questions to reflect your opinion as accurately as possible. Please put a tick mark on your answer. The date collected through this survey will be kept strictly confidential and will be sued for the academic research only.
Thank you very much for your time and opinion.

\section{Demographic information:-}

Name of the Participant:

Name of the Institute and Depart.

Semester/Trimester:

Age:

\section{Questionnaire}

1. Does this commercial help you to understand persuasive speech better? Y/ $\mathrm{N}$

2. Do you find the persuasive words in the commercial worthy of using in your persuasive speech? Y/N

3. Do you think the persuasive tone of the commercial can be incorporated into your persuasive speech? Y/N

4. Do you get any idea from the commercial of making your speech more creative? $\mathrm{Y} / \mathrm{N}$

5. Do you find the gesture, posture and facial expressions of the commercial useful for your persuasive speech? Y/N

6. Does this commercial help you to determine and apply the elements required to draw the attention of a particular audience? Y/N

7. Do you find learning persuasive speech through using TV commercial motivating and fun? $\mathrm{Y} / \mathrm{N}$ 